\title{
Trends in Inpatient Admission Comorbidity and Electronic Health Data: Implications for Resident Workload Intensity
}

\author{
Amanda V. Clark, MD'1, Charles M. LoPresti, MD², Todd I. Smith, MD, FHM²,3*
}

'Department of Medicine, University of Mississippi Medical Center, Jackson, Mississippi; ${ }^{M}$ Medical Service, Louis Stokes Cleveland VA Medical Center, Cleveland, Ohio; ${ }^{3}$ Department of Medicine, Case Western Reserve University School of Medicine, Cleveland, Ohio.

In the era of duty-hour regulations, there is increasing concern regarding resident workload compression. We conducted a retrospective, observational assessment of all internal medicine resident admissions to a Veterans Affairs hospital over a 15-year period to evaluate several admission components that impact resident workload and workload intensity, including electronic health record (EHR) data burden and patient comorbidity. A total of 67,346 admissions were included in the analysis. Mean patient comorbidity, as measured by the Charlson
Comorbidity Index, increased throughout the study period. EHR data burden, measured by numbers of notes, medications, and discharge summaries available per patient at the time of admission, also increased over the study period. These findings suggest that EHR data burden and comorbidity have increased over time, which impacts resident workload in the era of duty hour restrictions. Journal of Hospital Medicine 2018;13:570572. Published online first March 26, 2018. (C) 2018 Society of Hospital Medicine

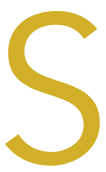
ince the Accreditation Council for Graduate Medical Education (ACGME) posed new duty hour regulations in 2003 and again in 2011, there have been concerns that the substantial compression of resident workload may have resulted in a negative learning environment. ${ }^{1-3}$ Residents are now expected to complete more work in a reduced amount of time and with less flexibility. ${ }^{4}$ In addition to time constraints, the actual work of a resident today may differ from that of a resident in the past, especially in the area of clinical documentation. ${ }^{5}$ Restricting resident work hours without examining the workload may result in increased work intensity and counter the potential benefits of working fewer hours. ${ }^{6}$ Measuring workload, as well as electronic health record (EHR)-related stress, may also help combat burnout in internal medicine. ${ }^{7}$ There are many components that influence resident workload, including patient census, patient comorbidities and acuity, EHR data and other available documentation, and ancillary tasks and procedures. ${ }^{7}$ We define resident workload intensity as the responsibilities required to provide patient care within a specified time. There is a paucity of objective data regarding the workload intensity of residents, which are essential to graduate medical education reform and optimization. Patient census, ancillary responsibilities, number of procedures, and conference length and frequency are some of the variables that can be adjusted by each residency program.

\footnotetext{
*Address for correspondence: Todd I. Smith, MD, FHM,Louis Stokes Cleveland Department of Veterans Affairs Medical Center, 10701 East Blvd 111(W), Cleveland, OH 44106; ; E-mail: Todd.Smith@va.gov

Received: July 31, 2017; Revised: December 14, 2017; Accepted: January 5, 2018
}

(C) 2018 Society of Hospital Medicine DOI 10.12788/jhm.2954
As a first step to objective measurement of resident workload intensity, we endeavored to evaluate the less easily residency program-controlled workload components of patient comorbidity and EHR data the time of patient admission.

\section{METHODS}

We conducted an observational, retrospective assessment of all admissions to the Louis Stokes Cleveland VA Medical Center (LSCVAMC) internal medicine service from January 1, 2000 to December 31, 2015. The inclusion criteria were admission to non-ICU internal medicine services and an admission note written by a resident physician. Otherwise, there were no exclusions. Data were accessed using VA Informatics and Computing Infrastructure. This study was approved by the LSCVAMC institutional review board.

We evaluated multiple patient characteristics for each admission that were accessible in the EHR at the time of hospital admission including patient comorbidities, medication count, and number of notes and discharge summaries. The Charlson Comorbidity Index (CCl) Deyo version was used to score all patients based on the EHR's active problem list at the time of admission. 8,9 The $\mathrm{CCl}$ is a validated score created by categorizing comorbidities using International Classification of Diseases, Ninth and Tenth Revisions. ${ }^{8}$ Higher $\mathrm{CCl}$ scores predict increased mortality and resource usage. For each admission, we also counted the number of active medications, the number of prior discharge summaries, and the total number of notes available in the EHR at the time of patient admission. Patient admissions were grouped by calendar year, the mean numbers of active medications, prior discharge summaries, and total available notes per patient during each year were calculated (Table). Data comparisons were completed between 2003 and 2011 as well as between 2011 and 2015; median data are also 
TABLE. Data Trends Among Internal Medicine Admissions

\begin{tabular}{|c|c|c|c|c|c|c|}
\hline & Trainee Admissions & $\mathrm{CCl}$ & Medical Problems & Notes & Medications & Discharge Summaries \\
\hline 2000 & 2,729 & 0.83 & 2 & 43 & 13.15 & 0.80 \\
\hline 2001 & 3,621 & 1.26 & 4 & 88 & 12.82 & 1.48 \\
\hline 2002 & 3,431 & 1.37 & 5 & 128 & 11.28 & 1.91 \\
\hline 2003 & 4,304 & $1.60(1)$ & $6(5)$ & $193(125)$ & $8.37(7)$ & $2.29(1)$ \\
\hline 2004 & 3,851 & 1.81 & 8 & 273 & 8.93 & 2.68 \\
\hline 2005 & 3,807 & 2.25 & 10 & 363 & 9.17 & 3.14 \\
\hline 2006 & 3,963 & 2.32 & 12 & 454 & 10.26 & 3.50 \\
\hline 2007 & 4,309 & 2.61 & 13 & 536 & 14.24 & 3.89 \\
\hline 2008 & 4,535 & 2.70 & 15 & 632 & 16.66 & 4.22 \\
\hline 2009 & 4,620 & 2.97 & 15 & 742 & 17.18 & 4.56 \\
\hline 2010 & 4,932 & 3.11 & 17 & 823 & 17.15 & 4.55 \\
\hline 2011 & 4,977 & $3.05(2)$ & $16(15)$ & $841(559)$ & $16.90(16)$ & $4.42(2)$ \\
\hline 2012 & 4,576 & 3.12 & 17 & 949 & 16.51 & 4.58 \\
\hline 2013 & 4,674 & 3.23 & 18 & 1,056 & 16.56 & 4.77 \\
\hline 2014 & 4,452 & 3.45 & 19 & 1,185 & 16.17 & 5.04 \\
\hline 2015 & 4,565 & $3.77(3)$ & $20(19)$ & 1,289 (819) & 16.49 (16) & $5.48(3)$ \\
\hline
\end{tabular}

Trainee admissions is the total number of admissions for the calendar year. All other data presented are mean measurements per patient at time of admission. Medians are listed in parentheses for 2003, 2011, and 2015.

provided for these years (Table). These years were chosen based on the years of the duty hour changes as well as comparing a not brand new, but still immature EHR (2003), a mature EHR (2011), and the most recent available data (2015).

\section{RESULTS}

A total of 67,346 admissions were included in the analysis. All parameters increased from 2000 to 2015 . Mean CCl increased from 1.60 in 2003 (95\% Cl, 1.54-1.65) to 3.05 in 2011 (95\% Cl, 2.97$3.13)$ and to 3.77 in 2015 (95\% Cl, 3.67-3.87). Mean number of comorbidities increased from 6.21 in $2003(95 \% \mathrm{Cl}, 6.05-6.36)$ to 16.09 in 2011 (95\% Cl, 15.84-16.34) and to 19.89 in 2015 (95\% $\mathrm{Cl}, 19.57-20.21)$. Mean number of notes increased from 193 in 2003 (95\% Cl, 186-199) to 841 in 2011 (95\% Cl, 815-868) and to 1289 in 2015 (95\% Cl, 1,243-1,335). Mean number of medications increased from 8.37 in 2003 (95\% Cl, 8.15-8.59) to 16.89 in 2011 (95\% Cl 16.60-17.20) and decreased to 16.49 in 2015 (95\% Cl, 16.18-16.80). Mean number of discharge summaries available at admission increased from 2.29 in 2003 (95\% Cl, 2.19-2.38) to 4.42 in 2011 (95\% Cl, 4.27-4.58) and to 5.48 in 2015 (95\% Cl, 5.27-5.69).

\section{DISCUSSION}

This retrospective, observational study shows that patient comorbidity and EHR data burden have increased over time, both of which impact resident workload at the time of admission. These findings, combined with the duty hour regulations, suggest that resident workload intensity at the time of admission may be increasing over time.

Patient comorbidity has likely increased due to a combination of factors. Elective admissions have decreased, and demographics have changed consistent with an aging population. Trainee admissions patterns also have changed over time, with less-acute admissions often admitted to nonacademic providers. Additionally, there are more stringent requirements for inpatient admissions, resulting in higher acuity and comorbidity.

As EHRs have matured and documentation requirements have expanded, the amount of electronic data has grown per patient, substantially increasing the time required to review a patient's medical record. ${ }^{5,10}$ In our evaluation, all EHR metrics increased between 2003 and 2011. The only metric that did not increase between 2011 and 2015 was the mean number of medications. The number of notes per patient has shown a dramatic increase. Even in an EHR that has reached maturity (in use more than 10 years), the number of notes per patient still increased by greater than 50\% between 2011 and 2015. The VA EHR has been in use for more than 15 years, making it an ideal resource to study data trends. As many EHRs are in their infancy in comparison, these data may serve as a predictor of how other EHRs will mature. While all notes are not reviewed at every admission, this illustrates how increasing data burden combined with poor usability can be time consuming and promote inefficient patient care. ${ }^{11}$ Moreover, many argue that poor EHR usability also affects cogni- 
tive workflow and clinical decision making, a task that is of utmost value to patient quality and safety as well as resident education. ${ }^{12}$

Common program requirements for internal medicine as set forth by the ACGME state that residency programs should give adequate attention to scheduling, work intensity, and work compression to optimize resident well-being and prevent burnout. ${ }^{13}$ Resident workload intensity is multifaceted and encompasses many elements, including patient census and acuity, EHR data assessment, components of patient complexity such as comorbidity and psychosocial situation, and time. ${ }^{13}$ The work intensity increases with increase in the overall patient census, complexity, acuity, or data burden. Similarly, work intensity increases with time restrictions for patient care (in the form of duty hours). In addition, work intensity is affected by the time allotted for nonclinical responsibilities, such as morning reports and conferences, as these decrease the amount of time a resident can spend providing patient care.

Many programs have responded to the duty-hour restrictions by decreasing patient caps. ${ }^{14}$ Our data suggest that decreasing patient census alone may not adequately mitigate the workload intensity of residents. There are other alternatives to prevent the increasing workload intensity that may have already been employed by some institutions. One such method is that programs can take into account patient complexity or acuity when allocating patients to teaching teams. ${ }^{14}$ Another method is to adjust the time spent on ancillary tasks such as obtaining outside hospital records, transporting patients, and scheduling follow-up appointments. Foregoing routine conferences such as morning reports or noon conferences would decrease work intensity, although obviously at the expense of resident education. Geographic rounding can encourage more efficient use of clinical time. One of the most difficult, but potentially impactful strategies would be to streamline EHRs to simplify and speed documentation, refocus regulations, and support and build based on the view of clinicians. ${ }^{15}$

The main limitations of this study include its retrospective design, single-center site, and focus on the internal medicine admissions to a VA hospital. Therefore, these findings may not be generalizable to other patient populations and training programs. Another potential limitation may be that changes in documentation practices have led to "upcoding" of patient comorbidy within the EHR. In addition, in this study, we looked only at the data available at the time of admission. To get a more complete picture of true workload intensity, understanding the day-to-day metrics of inpatient care would be crucial.

\section{CONCLUSION}

Our study demonstrates that components of resident workload (patient comorbidity and EHR data burden), specifically at the time of admission, have increased over time. These findings, combined with the duty-hour regulations, suggest resident workload intensity at the time of admission has increased over time. This can have significant implications regarding graduate medical education, patient safety, and burnout. To optimize resident workload, innovation will be required in the areas of workflow, informatics, and curriculum. Future studies to assess the workload and intensity of the course of the entire patient hospitalization are needed.

\section{Acknowledgments}

The authors thank Paul E. Drawz, MD, MHS, MS (University of Minnesota) for contributions in designing and reviewing the study.

Ethical approval: The study was approved by the Institutional Review Board at the LSCVAMC. The contents do not represent the views of the US Department of Veterans Affairs or the US government. This material is the result of work supported with resources and the use of facilities of the LSCVAMC.

Disclosures: The authors declare that they have no conflicts of interest to disclose.

\section{References}

1. Bolster L, Rourke L. The Effect of Restricting Residents' Duty Hours on Patient Safety, Resident Well-Being, and Resident Education: An Updated Systematic Review. J Grad Med Educ. 2015;7(3):349-363

2. Fletcher KE, Underwood W, Davis SQ, Mangrulkar RS, McMahon LF, Saint S. Effects of work hour reduction on residents' lives: a systematic review. JAMA. 2005; 294(9):1088-1100.

3. Amin A, Choe J, Collichio F, et al. Resident Duty Hours: An Alliance for Academic Internal Medicine Position Paper. http://www.im.org/d/do/6967. Published February 2016. Accessed November 30, 2017.

4. Goitein L, Ludmerer KM. Resident workload-let's treat the disease, not just the symptom. JAMA Intern Med. 2013;173(8):655-656.

5. Oxentenko AS, West CP, Popkave C, Weinberger SE, Kolars JC. Time spent on clinical documentation: a survey of internal medicine residents and program directors. Arch Intern Med. 2010;170(4):377-380.

6. Fletcher KE, Reed DA, Arora VM. Doing the dirty work: measuring and optimizing resident workload. J Gen Intern Med. 2011;26(1):8-9.

7. Linzer M, Levine R, Meltzer D, Poplau S, Warde C, West CP. 10 bold steps to prevent burnout in general internal medicine. J Gen Intern Med. 2014;29(1):18-20.

8. Charlson ME, Pompei P, Ales KL, MacKenzie CR. A new method of classifying prognostic comorbidity in longitudinal studies: development and validation. J Chronic Dis. 1987;40(5):373-383.

9. Deyo RA, Cherkin DC, Ciol MA. Adapting a clinical comorbidity index for use with ICD-9-CM administrative databases. J Clin Epidemiol. 1992;45(6):613-619.

10. Kuhn T, Basch P, Barr M, Yackel T, et al; Physicians MICotACo. Clinical documentation in the 21st century: executive summary of a policy position paper from the American College of Physicians. Ann Intern Med. 2015;162(4): 301-303.

11. Friedberg MW, Chen PG, Van Busum KR, et al. Factors Affecting Physician Professional Satisfaction and Their Implications for Patient Care, Health Systems, and Health Policy. Rand Health Q. 2014;3(4):1.

12. Smith SW, Koppel R. Healthcare information technology's relativity problems: a typology of how patients' physical reality, clinicians' mental models, and healthcare information technology differ. J Am Med Inform Assoc. 2014; 21(1):117-131.

13. ACGME Program Requirements for Graduate Medical Education in Internal Medicine. http://www.acgme.org/Portals/O/PFAssets/ProgramRequirements/140_internal_medicine_2017-07-01.pdf. Revised July 1, 2017. Accessed July 22, 2017.

14. Thanarajasingam U, McDonald FS, Halvorsen AJ, et al. Service census caps and unit-based admissions: resident workload, conference attendance, duty hour compliance, and patient safety. Mayo Clin Proc. 2012;87(4):320-327.

15. Payne TH, Corley S, Cullen TA, et al. Report of the AMIA EHR-2020 Task Force on the status and future direction of EHRs. J Am Med Inform Assoc. 2015;22(5):1102-1110. 